\title{
Stepper Motor Applications Across Electrical Engineering Technology Curriculum
}

\author{
Ilya Grinberg, D. Steven Barker, Stephanie Goldberg, Ronald Matusiak, \\ David Andruczyk \\ State University of New York College at Buffalo
}

\section{Introduction}

Industrial, commercial and institutional facilities have grown significantly more complex in the last decade. The rising level of technologies and equipment utilized in these facilities has complicated the elements of their engineering maintenance and operation. As an example of such technologies, consider robotics applications used in a variety of industries.

Stepper motors are a major component of many robotics applications. The complexity of any engineering system's structure depends on many factors. Examples of these for the design of stepper motor (SM) applications are: 1) the level of the technical progress in the particular application, 2) manufacturing technology requirements, 3) safety and environmental factors, 4) equipment and machines used in the process, 5) economic considerations. The systems approach is imperative in that it coordinates the elements of a SM application, the elements of other engineering applications of the project as well as the elements of the involved economic infrastructure. ${ }^{1}$ The diagram which illustrates the coordination between these systems activities is shown in Figure 1. Table 1 provides a short description of the SM intercommunications labeled on the diagram.

The electrical engineering (EE) section represents all aspects of the electrical segment of a SM application. Applying systems categories, the authors consider the EE section as a system. However, the EE system consists of various subsystems that differ by function and by content. These subsystems are:

a) Electric Machines subsystem - responsible for research, design, selection, installation, adjustment, operation, and maintenance of a stepper motor as a rotating machine;

b) Digital Circuits subsystem - responsible for the sequential excitation of motor windings in response to signals from the control subsystem.

c) Electronic Power Driver subsystem - responds to excitation signals from the digital circuit. This subsystem is also responsible for handling of coil currents and suppression of inductive voltage spikes.

d) Control subsystem - responsible for control system design, optimization, stability and performance analysis.

\section{Teaching Methodology}

Education of new specialists and training of existing ones is a significant part of the successful development and operations of any engineering system. For SM applications, all major elements 


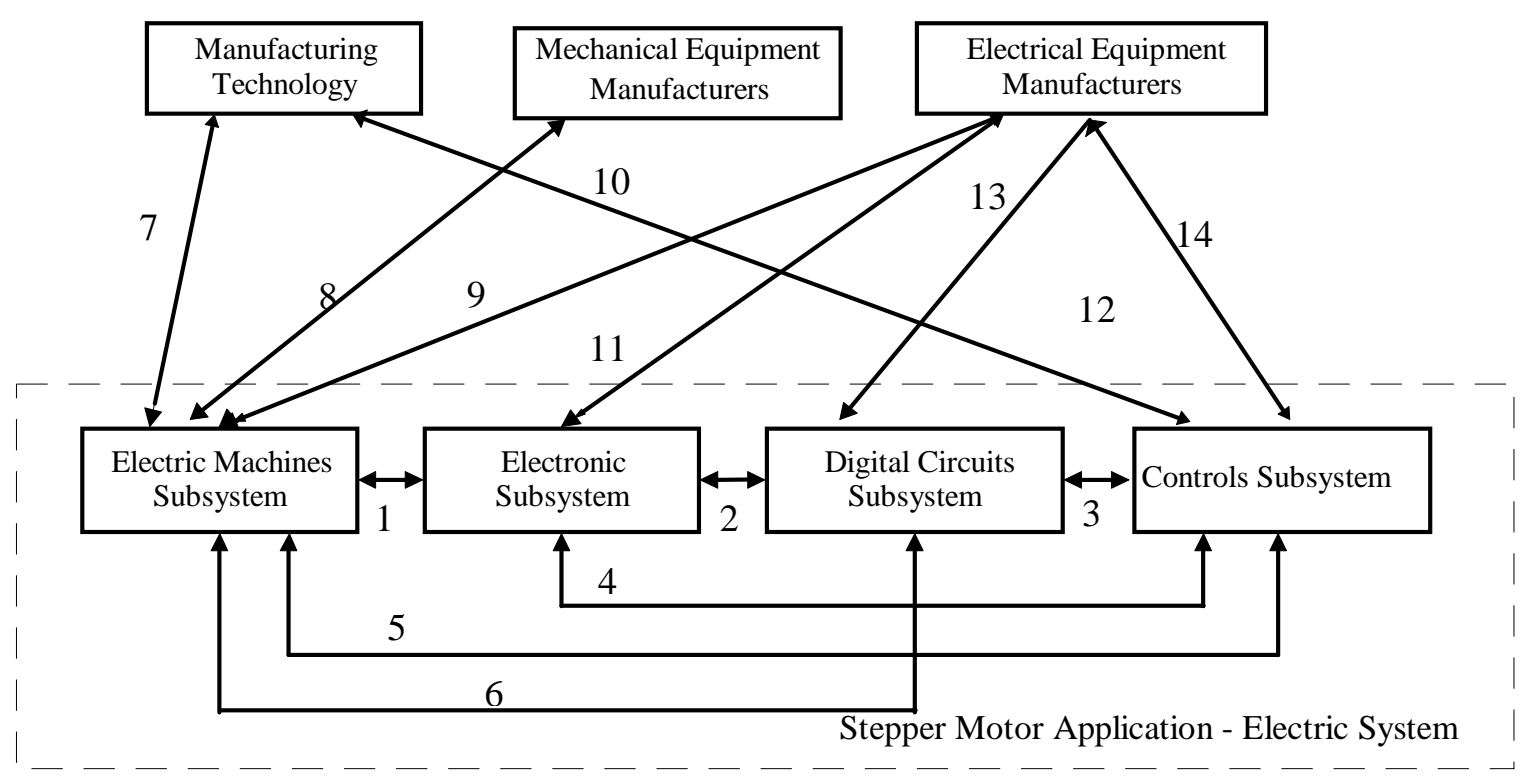

Fig. 1. The diagram of interrelationships of Stepper Motor Application systems activities

Table 1. Description of the Stepper Motor Application Intercommunications

\begin{tabular}{|l|l|}
\hline Number & \multicolumn{1}{|c|}{ Description } \\
\hline 1 & $\begin{array}{l}\text { SM drive requirements, such as coil current, coil voltage, motor winding } \\
\text { information, step speed. }\end{array}$ \\
\hline 2 & Digital interface for excitation control. \\
\hline 3 & Digital interface for step-command pulses and other control signals. \\
\hline 4 & $\begin{array}{l}\text { Utilization of specific electrical signals in the control subsystem provided } \\
\text { through the external connections. The control subsystem will be controlling } \\
\text { specific electrical signals to achieve the desired control specifications. }\end{array}$ \\
\hline 5 & $\begin{array}{l}\text { SM design features, such as size, inertia, number of steps, angle per step are } \\
\text { inputs for the control subsystem design and operation. }\end{array}$ \\
\hline 6 & $\begin{array}{l}\text { Command pulse specification; SM drive requirements, such as step speed. } \\
\text { operations. }\end{array}$ \\
\hline 7 & $\begin{array}{l}\text { Requirements for dimensions, paths for electric wiring, information on } \\
\text { mechanical characteristics of the load (mass, moment of inertia among } \\
\text { others). }\end{array}$ \\
\hline 8 & $\begin{array}{l}\text { Utilization of available electrical components manufactured by vendors and } \\
\text { suppliers. }\end{array}$ \\
\hline 9,11, & $\begin{array}{l}\text { Influence of manufacturing requirements on the control systems design. Slight } \\
\text { changes in manufacturing procedures can make large impacts on the control } \\
\text { system }\end{array}$ \\
\hline 13,14 & $\begin{array}{l}\text { Information on mechanical limitations of the SM and mechanical connections } \\
\text { of the load to the SM for control purposes. }\end{array}$ \\
\hline 12 &
\end{tabular}


of a system as well as its interrelationships with the elements of the economic infrastructure should be covered by a syllabus. The courses in electric machines, electronics, digital systems, and control systems offered by Buffalo State College include detailed considerations of each subsystem covered by the corresponding course and their interrelations covered across curricula.

The content and primary features of incorporating SM applications across the Electrical Engineering Technology curriculum are:

- introduction of systems engineering principles and concepts to students

- principles and basics of SM as a rotating machine

- large loads such as rotating machinery that must be controlled by a transistor switch

- inductive loads requiring voltage spike protection

- the role of transistor power switching as an interface between digital control signals and large loads

- open-loop control and closed-loop control for specific SM applications

- a PLC as a driver for the SM and PLC programming

- the sequencer capabilities of PLC programming as the central focus of the PLC's capability to drive the SM

- Speed of rotation as a function of the rate at which control signals are received from the control subsystem.

- Position accuracy as related to the rate of stepping and the relative torque.

The systems approach enables students to see the "big picture" and allows better understanding of instructions presented.

\section{Student Project}

The systems approach was implemented in the classroom in the Electrical Engineering Technology program at Buffalo State College. A student project was used to test the success of this instructional method. The objective of the project was to design, build, and test a low-cost controller for unipolar and bipolar stepper motors. The electronic and digital circuit design as well as provisions to interface with the control circuits were among the project requirements. The students utilized the motor specifications (number of coils, coil current/voltage, step size) to make their component selections. During the design process, students were required to functionally test each subsystem of their application and to insure proper interfacing between subsystems.

The project was very successful as evaluated by the students who completed the project and the supervising faculty. ${ }^{2}$

In general, student opinions were as follows:

- The project was an overall positive experience. The students liked the idea of working on a real-life project.

- The students found it interesting to complete a design from beginning to end using many of techniques learned in related courses. 
- The project made students aware of the efforts that must go into designing, creating, and implementing a complicated engineering system, such as a SM application. The students have gained more respect and appreciation for such work.

- The systems approach was an excellent tool for recognizing and utilizing many interrelationships between different elements and subsystems and definitely helped to come up with a better solutions.

One of the most successful designs involved a SM controller for video camera positioning. A cyclic phase excitation pattern was selected to provide repetitive scan motion for one or two cameras. An electrically programmable read-only memory (EPROM) and counting circuit were selected to implement this motion. Power transistors (specifically MOSFETs) were used to drive the motor coils. Provisions were made to interface with the control subsystem to remotely operate video cameras in multi-media presentations. ${ }^{2}$

\section{Demonstration Unit}

To demonstrate the concepts being used in the SM applications of the Electrical Engineering Technology (EET) curricula, the authors developed a fully-functional demonstration unit. The block diagram of the unit is presented in Fig. 2.

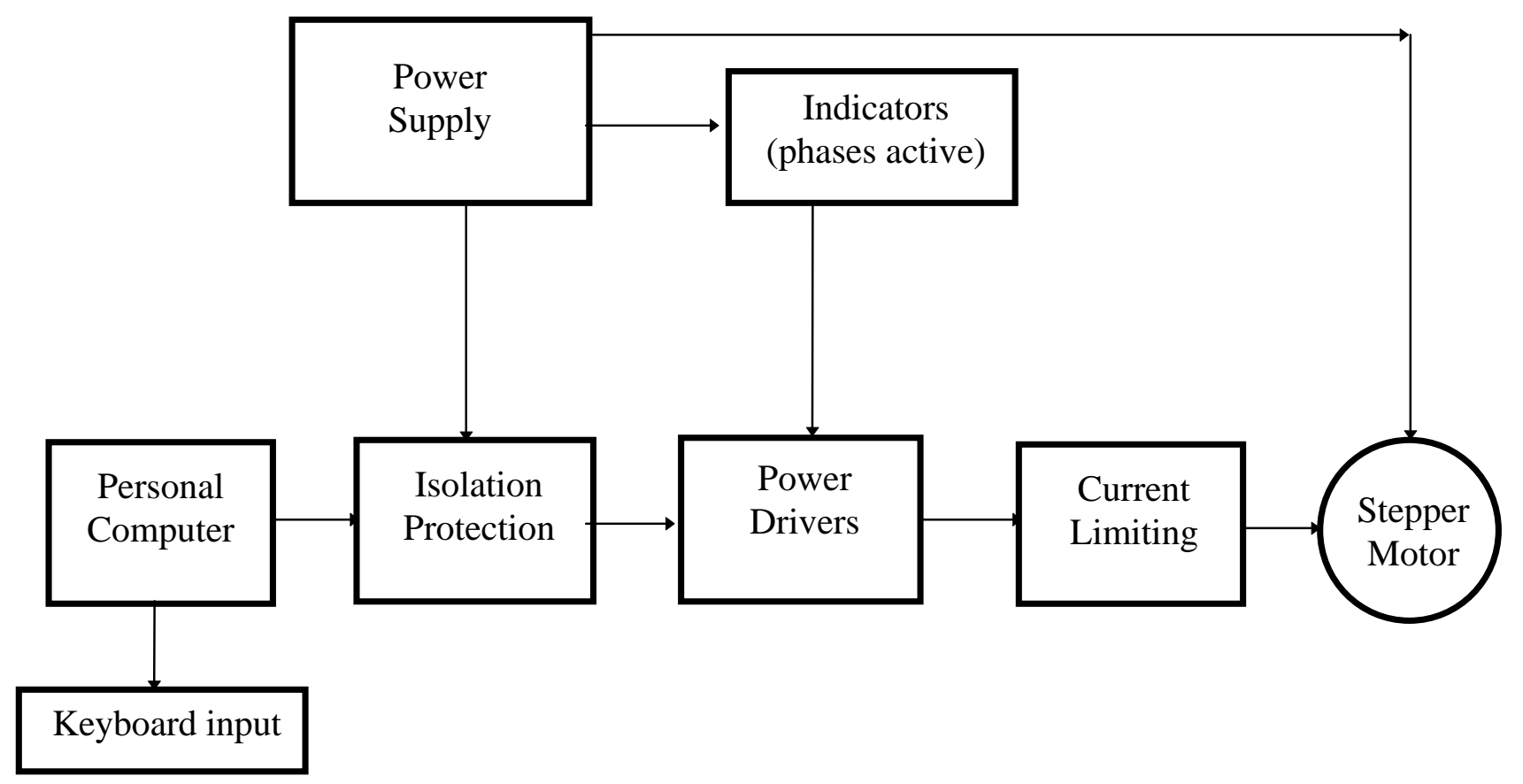

Fig. 2 Block diagram of the Demonstration Unit

The Stepper Motor control circuit contains the following functional blocks:

1) Computer Printer Port Interface.

2) Electrical Isolation. 
3) Power Drivers and Current Limiting.

4) Coil Activation Indicator.

The computer printer port provides the logic level stimulus, which, when conditioned, will cause the stepper motor to rotate. The stator coils of the stepper motor must be energized in the proper sequence. The program being executed on the computer (PC) is the sequence generator. It supplies the proper levels and timing necessary to cause shaft rotation. The flow-chart of the program is presented in Fig. 3.

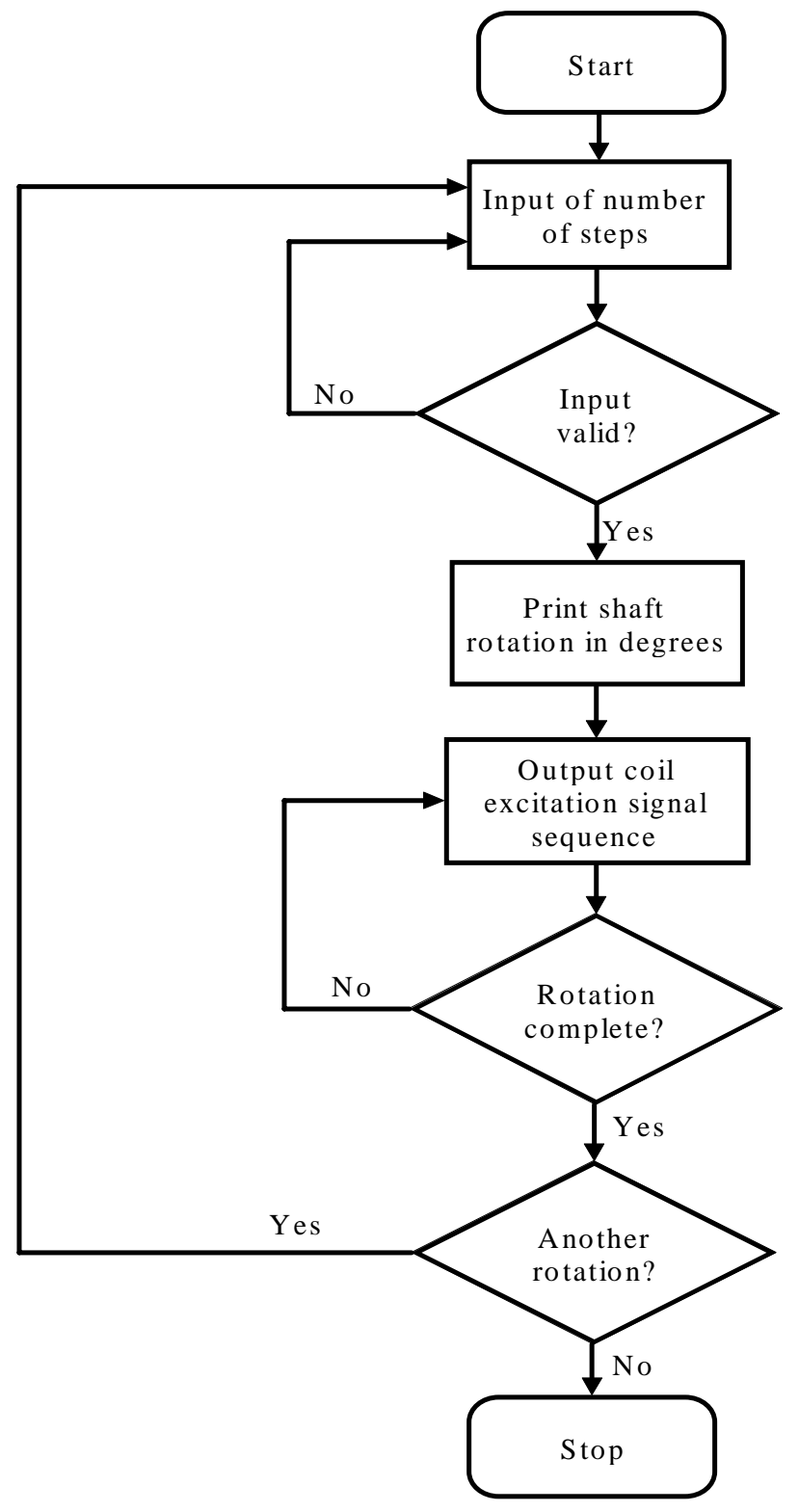

Fig. 3. Flow chart of the stepper motor coil excitation 
Opto-isolators are used to protect the PC's printer port from being damaged by voltages that might be present in the driver circuit. They also effectively isolate the PC from unwanted noise generated by switching currents. The power transistors provide drive current directly to the motor coils. They are high current-handling devices. The opto-isolators have a darlington-pair output that is sufficient to cause the power transistors to turn on. The light-emitting diodes (LEDs) provide a visual indication of coil activity. This allows observation of the step sequence when the motor is rotated at low speed.

\section{Simulation-Based Approach}

With the systems approach in mind, it is desirable to supply students with a tool to aid in the stepper motor selection and analysis process. The most efficient approach would be to provide a computer simulation program that allows students to exercise a motor under conditions it would be subjected to in a real-world application. The program should have a number of components from which students can select. A system designed by students would be put through a series of tests to quantify certain parameters of motor and circuit performance. Some of the parameters include starting torque and current, running torque and current, holding torque and current, maximum rotation speed and maximum duty cycle limit among others.

A simulation of a SM system was made using the Electronic Workbench ${ }^{\circledR}$ software package. It was decided to provide a visual and interactive approach to the study of stepper motors considering the limited amount of hardware available. A circuit was simulated to show the basic characteristics of stepper motor operation.

The circuit provided a visual indication of rotation with simulated LEDs arranged in circular form corresponding to the motor shaft position. Another set of simulated LEDs indicated which motor coils were energized and thus students could observe the coordination between driver and motor. With this program, it is possible for students to modify the circuit and observe the responses.

\section{Conclusion.}

Today's complex systems that include high-current loads and application-oriented controls dictate the combined efforts of faculty, staff, and students in the preparation of well-educated specialists. The experience of stepper motor applications across the EET curriculum brings a better engineering practice to the classroom changing the questions from "what" and "how" to mind enhancing and knowledge stimulating "what if."

\section{References.}

1. Grinberg, I., and Stratton, J. "A Systems Engineering Approach to Engineering Design Methodology." Journal of Engineering Technology 13, No 2 (Fall 1996): 8- 13

2. Buffalo State College. Final Reports on Student Projects. Stepper Motor Application. Buffalo, NY: Buffalo State College, 1996 


\section{Biographies.}

ILYA GRINBERG graduated from the Lvov Polytechnic Institute (Lvov, Ukraine) with a MS in EE and earned a Ph.D. degree from the Moscow Institute of Civil Engineering (Moscow, Russia) with a specialization in systems engineering and design automation. He has 20 years of industrial experience in design and consulting in the field of power distribution systems and design automation. Currently he is an assistant professor of Engineering Technology at the State University of New York College at Buffalo. He is a member of IEEE, a member of ASEE and a member of the International Council on Systems Engineering (INCOSE). His interests are in the field of power distribution systems, computerized design, and systems engineering.

D. STEVEN BARKER graduated from University of Wyoming with an MS in Physics and a Ph. D. in Electrical Engineering. His has 10 years of experience in the aerospace industry and 11 years in academia. Currently he is an assistant professor of Engineering Technology at the State University of New York College at Buffalo. His interests are in industrial controls and automation. He is a member of IEEE.

STEPHANIE GOLDBERG graduated from the University of Buffalo with MS and Ph.D in Electrical and Computer Engineering. She has 10 years of industrial experience in the area of defense electronics and 6 years of teaching undergraduate courses in electronics and digital circuits. Currently she is a faculty member at the State University of New York College at Buffalo. Her current interests are in fault-tolerant computer systems and analog circuits. She is a member of IEEE.

RONALD MATUSIAK graduated from the University of Buffalo with a BSEE. He has 13 years of industrial experience in digital and analog design with the Sierra Technologies. Currently he is an instructional support specialist for the Department of Technology at the State University of New York, College at Buffalo.

DAVID ANDRUCZYK is a full time undergraduate student in the Electrical Engineering Technology program at the State University of New York College at Buffalo. He works as a system administrator for the college library computer network. His plans are to work in the field of electrical engineering design and to continue education at the graduate level. 